\title{
SERVQUAL DALAM PELAYANAN KELAS PADA LABORATORIUM MANAJEMEN
}

\author{
Haryadi Sarjono; Natalia \\ Management Department, School of Business Management, BINUS University \\ Jln. K. H. Syahdan No. 9, Palmerah, Jakarta Barat 11480 \\ haryadi_s@binus.edu; natalia@binus.edu
}

\begin{abstract}
This study aims to determine how the quality service class of Laboratory School of Business Management (SoBM), Bina Nusantara University to students majoring in management science to management courses (Quantitative Business Analysis). SoBM has 3 campuses spreading across West Jakarta and Tangerang, which are as much as 2 campuses in West Jakarta and 1 campus in Alam Sutra area (Tangerang). The research was only conducted on campus Alam Sutra (Tangerang) which is relatively new, consisted only 1 class (42 students) that the specialization is entrepreneurship management science courses. This study applied Servqual method which is a measure of customer satisfaction through gap analysis, developed by Parasuraman, Zeithaml, and Berry. Respondents in this study consisted of 42 students who all as population. The results showed that all Servqual dimensions have an unsatisfactory quality. This can be seen from all the negative gaps in dimension tangibles, reliability, responsiveness, assurance and empathy. From all the negative values, reliability dimension (-6.58) has a gap with the highest negative value or the least satisfactory quality
\end{abstract}

Keywords: serqual, Gap analysis, science management, service quality, laboratory

\begin{abstract}
ABSTRAK
Penelitian ini bertujuan untuk mengetahui kualitas pelayanan kelas pada Laboratorium School of Business Management (SoBM), Bina Nusantara University kepada mahasiswa jurusan manajemen untuk mata kuliah manajemen sains (Analisis Kuantitatif Bisnis). SoBM mempunyai 3 kampus yang tersebar di Jakarta Barat dan Tangerang, yaitu sebanyak 2 kampus di Jakarta Barat dan 1 kampus, didaerah Alam Sutra (Tangerang). Penelitian ini hanya dilakukan di kampus Alam Sutra (Tangerang) yang relatif baru, yang hanya terdiri 1 kelas (42 mahasiswa) peminatan entrepreneurship yang ada mata kuliah manajemen sains. Dalam penelitian ini menerapkan metode Servqual yang merupakan alat ukur kepuasan pelanggan melalui analisis gap yang dikembangkan oleh Parasuraman, Zeithaml, dan Berry. Responden dalam penelitian ini terdiri dari 42 mahasiswa yang semuanya sebagai populasi. Hasil penelitian didapatkan bahwa semua dimensi Servqual memiliki kualitas yang tidak memuaskan. Hal ini terlihat dari semua gap yang bernilai negatif pada dimensi tangibles, reliability, responsiveness, assurance dan empathy. Dari semua nilai negatif tersebut dimensi, reliability $(-6,58)$ memiliki gap dengan nilai negatif tertinggi atau kualitas yang paling tidak memuaskan
\end{abstract}

Kata kunci: serqual, analisis Gap, analisa kuantitatif bisnis, kualitas pelayanan, laboratorium. 


\section{PENDAHULUAN}

Sekarang ini lingkungan bisnis relatif berbeda dengan generasi sebelumnya, baik dalam cara pemasaran, proses pelayanan, maupun produk. Tempat transaksi penjualan menjadi makin global, persaingan atarindustri sejenis makin tajam, dan konsumen lebih cerdas, makin pintar karena informasi yang luas dan juga lebih menuntut (Parasuraman, 1988, Lovelock \& Wright, 1999; Kandampully \& Butler, 2001). Hal yang diperlukan banyak produsen adalah beberapa bentuk strategi yang dapat menghasilkan keunggulan kompetitif yang berkelanjutan, mengingat bersaing semata-mata atas dasar variabel bauran pemasaran tradisional tidak lagi memadai atau efektif (Parasuraman, et al, 1994). Untuk mencapai keunggulan kompetitif, banyak organisasi bisnis, terutama dalam industri jasa, berfokus pada kualitas pelayanan (Dotchin \& Oakland, 1994; McColl, Callaghan \& Palmer, 1998). Inilah pergeseran minat berasal dari hubungan kualitas pelayanan terhadap beberapa konstruksi penting. Pertama-tama, kualitas layanan secara positif terkait dengan kepuasan pelanggan (Kellogg, Youngdahl \& Bowen, 1997; Roest \& Pieters, 1997; dalam Hoe, 2004). Kedua, kualitas layanan yang unggul memengaruhi niat pembelian kembali (Taylor \& Baker, 1994; Zeithaml, Berry \& Parasuraman, 1996). Ketiga, kualitas layanan memiliki dampak positif pada loyalitas pelanggan dan retensi pelanggan (Boshoff, 1997; Boulding, Kaira, Staelin \& Zeithaml, 1993). Kepuasan pelanggan juga lebih mungkin untuk memberikan rekomendasi positif dari mulut ke mulut kepada pelanggan potensial (DiDomenico \& Bonnici, 1996; Ghobadian, Speller \& Jones, 1994; Zeithaml et al, 1996). Ada juga bukti bahwa kualitas layanan yang unggul mengarah ke pangsa pasar yang lebih besar, laba atas investasi dan pengurangan biaya (Gumus \& Koleoglu, 2002). Idenya adalah bahwa kualitas layanan yang unggul pada akhirnya akan diterjemahkan ke dalam kinerja keuangan yang akan meningkat dan ujungnya adalah keuntungan bagi organisasi (Jumus \& Koleoglu, 2002; Zeithaml, 2000; dalam Hoe, 2004). Hal ini juga akan menciptakan keunggulan kompetitif yang berkelanjutan karena perusahaan yang siap dalam penyediaan kualitas pelayanan pada akhirnya akan mengembangkan reputasi yang sangat sulit untuk ditiru oleh pesaingnya (Rapert \& Wren, 1998).

Kepentingan dalam kualitas pelayanan juga menemukan jalan ke dunia industri pendidikan (Kelsey \& Bond, 2001; Pariseau \& McDaniel, 1997). Alasan utama untuk kepentingan ini adalah kenyataan bahwa di banyak bagian dunia, lingkungan lembaga pendidikan, khususnya pendidikan tinggi yang beroperasi, telah menjadi makin kompetitif dan sulit untuk mengatasi (Conway, Mackay \& Yorke, 1994; Cuthbert 1996; Ford, Joseph \& Joseph, 1999; Palmer, 2001; dalam Hoe, 2004). Globalisasi pasar telah membawa peningkatan jumlah perguruan tinggi di banyak negara, dan hal ini telah mengakibatkan persaingan yang ketat bagi siswa antara penyedia pendidikan tinggi. Untuk membuat keadaan menjadi lebih baik, banyak lembaga pendidikan tinggi harus bersaing dengan dana pemerintah yang relatif makin berkurang dari tahun ke tahun dan juga sistem pendanaan yang terkait dengan kinerja kelembagaan (O'Brien \& Deans, 1996; Soutar \& McNeil, 1996; Waugh, 2002). Selain itu, diketahui banyak masyarakat yang menuntut kepada lembaga pendidikan tinggi untuk menggunakan praktik-praktik pengelolaan sektor swasta agar menjadi lebih efisien dan kompetitif (Galloway, 1998).

Berdasarkan uraian, Bina Nusantara University (UBinus) sebagai sebuah lembaga pendidikan tinggi swasta yang berada di Jakarta Barat mencoba mengarah kepada kepuasan konsumen yang dalam hal ini adalah mahasiswa. Riset meneliti keberadaan laboratorium (Lab) manajemen yang berada di bawah naungan School of Business Management (SoBM) yang tiap semester memberikan layanan berupa pelatihan, khususnya pelatihan Analisis Kuantitatif Bisnis (AKB), kepada mahasiswa semester lima. Peneliti mencoba untuk menelaah kasus kepuasan konsumen (serqual), yaitu seberapa puas komsumen (mahasiswa) terhadap pelayanan yang diberikan oleh para asisten dosen Lab AKB. Analisis kuantitatif bisnis merupakan sebuah metode pendekatan sains yang memuat konsep dasar perhitungan secara matematika untuk memecahkan suatu masalah dalam pengambilan keputusan bisnis. Analisis tersebut dapat memberikan gambaran nyata tentang suatu permasalahan operasional 
dalam proses produksi suatu barang atau jasa. Pendekatan ini menggunakan data mentah, yang terdapat proses input-output terhadap sebuah data hingga dapat diolah menggunakan komputer dan menjadi informasi bermanfaat bagi pengguna. Saat ini Bina Nusantara University memberikan mata kuliah Lab. Manajemen Sains guna membantu mahasiswa untuk mengerjakan data-data mentah yang diberikan oleh pengajar (assiten dosen Lab). Mahasiswa dapat menggunakan aplikasi khusus di perangkat komputer untuk mentransformasi sebuah data mentah melalui serangkaian mekanismeproses input menjadi output pada sebuah data.

Mahasiswa akan dapat membandingkan dan menganalisis secara bisnis hasil penghitungan kuantitatif dan menghubungkannya dengan manfaat yang akan mereka capai. Manajemen sains juga membantu mahasiswa menghitung rasio keuangan dari balance sheet sebuah data, serta menganalisis arus kas dari sebuah perusahaan. Dengan menerapkan kaidah-kaidah matematika dalam proses menguraikan model kuantitatif operasional suatu proses produksi yang berkaitan langsung dalam pengambilan keputusan, maka hasil data itulah yang menjadi jantung dari analis akuantitatif dengan proses yang cepat dan tepat. Untuk mendukung kegiatan belajar pada mata kuliah tersebut, dibutuhkan fasilitas berupa peralatan komputer berupa laboratorium komputer, mengingat banyaknya perhitungan data-data yang harus dipecahkan dan diselesaikan oleh mahasiswa dengan durasi waktu pembelajaran yang terbatas, maka sangat pentingnya penggunaan komputer untuk menganalisa data kuantitatif dalam pengambilan keputusan bagi mahasiswa. Kelas Lab. Analisis Kuantitatif Bisnis dapat membantu mahasiswa lebih paham dan mengerti berbagai macam model data sehingga bisa memecahkan data tersebut dengan tanpa membuang waktu durasi pembelajaran. Ketika terdapat kesulitan dan perbedaan hasil penghitungan sebuah data antara penghitungan manual dan komputer, maka hasil dari penghitungan komputer akan dapat dipercaya dan dipertanggungjawabkan untuk mengambil keputusan.

Dari uraian permasalahan, maka dapat diidentifikasi permasalahan dalam penelitian ini, yaitu sebagai berikut. Pertama, bagaimana ekspektasi mahasiswa jurusan manajemen Bina Nusantara University terhadap kualitas pelayanan/jasa pada kelas Lab. Analisis Kuantitatif Bisnis? Kedua, bagaimana persepsi mahasiswa jurusan manajemen Bina Nusantara University terhadap kualitas pelayanan/jasa pada kelas Lab. Analisis Kuantitatif Bisnis? Ketiga, berapa besar gap servqual antara persepsi dengan ekspektasi mahasiswa jurusan manajemen Bina Nusantara University terhadap kualitas pelayanan/jasa pada kelas Lab. Analisa Kuantitatif Bisnis? Keempat, faktor apa yang harus ditingkatkan dalam kualitas pelayanan/jasa dari jurusan manajemen Bina Nusantara University terhadap kelas Lab. Analisa Kuantitatif Bisnis?

\section{Landasan Teori}

Kualitas merupakan salah satu kunci dalam memenangkan persaingan dengan pasar. Ketika perusahaan telah mampu menyediakan produk berkualitas maka telah membangun salah satu fondasi untuk menciptakan kepuasan pelanggan. Menurut Goetsh dan Davis yang dikutip oleh Arief (2007), kualitas merupakan suatu kondisi dinamis yang berhubungan dengan produk, jasa, manusia, proses dan lingkungan yang memenuhi atau melebihi harapan. Menurut Crosby yang dikutip oleh Yamit (2010), kualitas adalah sebagai nihil cacat, kesempurnaan dan kesesuaian terhadap persyaratan. Menurut Kotler (2009), kualitas adalah totalitas fitur dan karakteristik produk atau jasa yang bergantung pada kemampuannya untuk memuaskan kebutuhan yang dinyatakan atau tersirat. Hal ini jelas merupakan definisi yang berpusat pada pelanggan. Berdasarkan definisi tersebut dapat disimpulkan bahwa kualitas merupakan suatu kondisi dasar yang berhubungan dengan produk, jasa, manusia, proses dan lingkungan dalam memenuhi harapan sesuai terhadap spesifikasi yang ada bergantung pada kemampuan untuk menghasilkan kepuasan pelanggan.

Menurut Kotler (2000:428) jasa (service) adalah: “a service is any act or performance that one party can offer to another that is essentially intangible and does not result in the ownership of anything. It's production may or may not be tied to a pshyical product." Sedangkan Zeithaml dan 
Bitner (2003:3) mengemukakakn definisi jasa sebagai berikut: "include all economic, activities whoise output is not physical product or construction is generally consumed at the time it's produced and provided added value in forms (such as convenience, amusement, timeliness, comfort or health) that are essentially intangible concerns of it 's first purchase." Berdasarkan beberapa definisi, maka jasa pada dasarnya adalah sesuatu yang mempunyai ciri-ciri: (1) tidak berwujud namun dapat memenuhi kebutuhan konsumen, (2) proses produksi jasa dapat menggunakan atau tidak menggunakan bantuan, (3) suatu produk fisik, (4) jasa tidak mengakibatkan peralihan hak atau kepemilikan, dan (5) terdapat interaksi antara penyedia jasa dengan pengguna jasa.

Jasa memiliki empat karakteristik unik yang membedakannya dari barang. Karakteristik tersebut berdampak pada strategi pengelolaan pemasaran. Empat karakteristik utama tersebut dinamakan IHIP paradigm, yaitu Intangibility, Heterogeneity, Inseparability, dan Perishability (Tjiptono \& Chandra, 2011:35).

Dalam rangka melakukan survei tentang kepuasan pelanggan, Zeithaml et al (1990) menyebutkan sepuluh kriteria atau dimensi yang menjadi perhatian pelanggan sehubungan penilaian atas kualitas pelayanan. Sepuluh dimensi itu adalah tampilan (tangibles), keandalan (reliability), tanggap (responsiveness), kompetensi (competency), kesopanan (courtesy), kepercayaan (credibility), keamanan (security), keterbukaan (access), komunikasi (communication), dan mengerti pelanggan (understanding the customer). Kemudian, sepuluh kriteria memiliki lima dimensi yang di dalamnya mencakup sepuluh kriteria tersebut.

Kualitas jasa harus dimulai dari kebutuhan pelanggan dan berakhir dengan kepuasan pelanggan serta persepsi positif terhadap kualitas jasa. Sebagai pihak yang membeli dan mengkonsumsi jasa, pelanggan yang menilai tingkat kualitas jasa sebuah perusahaan (Tjiptono dan Chandra, 2011:180).

Dalam konteks kualitas produk (barang dan jasa) dan kepuasan pelanggan, consensus telah dicapai bahwa harapan pelanggan (customer expectation) memainkan peran penting sebagai standar perbandingan dalam mengevaluasi kualitas maupun kepuasan. Menurut Olson dan Dover, ekspektasi pelanggan merupakan keyakinan pelanggan sebelum mencoba atau membeli suatu produk, yang dijadikan standar atau acuan dalam menilai kinerja produk bersangkutan (Tjiptono \& Chandra, 2011:181).

Kata kepuasan (satisfaction) berasal dari bahasa latin yang terdiri dari dua unsur kata, yaitu satis yang artinya cukup baik atau memadai dan facio yang memiliki arti melakukan atau membuat. Kepuasan bisa diartikan sebagai upaya pemenuhan sesuatu atau membuat sesuatu memadai (Tjiptono \& Chandra, 2011). Konsep kepuasan konsumen sendiri bersifat abstrak. Pencapaian kepuasan dapat merupakan suatu proses yang sederhana maupun kompleks dan rumit. Peranan setiap individu di dalam suatu organisasi atau perusahaan dalam pemberian service kepada konsumen akan sangat penting dan berpengaruh terhadap kepuasaan yang terbentuk (Arief, 2007).

Menurut Noel, "Satisfied customers are often repeat purchasers and this leads to greater profitability." Maksud pernyataan tersebut yaitu konsumen atau pelanggan yang merasa puas merupakan pembeli yang melakukan pembelian secara rutin; dan hal ini menghasilkan keuntungan yang lebih besar bagi perusahaan (Noel, 2009).

Menghitung atau menentukan kualitas layanan terhadap industri jasa, jauh lebih sulit daripada produk industri manufaktur (Palmer, 2001). Kesulitan ini terlihat pada sebagian besar menghitung hasil dari item intangibility layanan yang sangat kontras dengan produk dari industri manufaktur (Bebko, 2000; Gronroos, 2001). Sementara kualitas barang yang diproduksi dapat dikenakan spesifikasi objektif dan karenanya dengan mudah dievaluasi oleh pelanggan, kualitas layanan hanya dapat dinilai dengan cara subjektif (Pariseau 8c McDaniel, 1997; Soutar \& McNeil, 1996; dalam Hoe, 
2004). Hal ini dianggap mengecewakan pada skala kontinum oleh pelanggan (Ghobadian et al., 1994). Kurangnya item tangibility menyebabkan kedua penyedia layanan dan pelanggan akan mengalami tingkat ketidakpastian tertentu ketika mengitung untuk mengevaluasi kualitas layanan (Lovelock \& Wright, 1999). Akibatnya, hampir mustahil untuk menentukan kualitas layanan dengan presisi yang tepat (Philip \& Hazlett, 1997; Sureshchandar et al, 2002).

Servqual merupakan model pengukuran gap kualitas pelayanan/jasa (service quality) yang diperkenalkan oleh Zeithaml, Parasuraman dan Berry dalam Gaspersz (2012). Model yang dikenal dengan istilah gap analysis model ini berkaitan erat dengan model kepuasan pelanggan yang didasarkan pada rancangan diskonfirmasi (attribute performance) yang meningkat lebih besar daripada harapan (expectations) terhadap atribut bersangkutan, maka persepsi terhadap kualitas pelayanan/jasa akan positif atau sebaliknya (Tjiptono \& Chandra, 2011). Parasuraman, Zeithaml dan Berry dalam Tjiptono dan Chandra (2011) memaparkan secara rinci lima gap kualitas jasa yang berpotensi menjadi sumber masalah kualitas jasa. Model yang dinamakan Servqual (service quality) dikembangkan dengan maksud untuk membantu para manajer dalam menganalisis sumber masalah kualitas dan memahami cara-cara memperbaiki kualitas jasa. Selain itu juga servqual digunakan sebagai instrumen diagnostik untuk mengetahui pencapaian kualitas servis yang berasaskan model konsepsual kualitas servis yang diperkenalkan oleh Parasuraman et al. (1985). Model Servqual juga telah dibangun Parasuraman, Zeithaml, dan Berry (1988) untuk mengukur kualitas servis. Menurut Parasuraman et al. (1988), kualitas servis adalah kemampuan organisasi untuk memenuhi atau mengatasi harapan pelanggan, di mana harapan pelanggan diartikan sebagai keinginan dan kehendak pelanggan. Dalam hal ini kualitas jasa yang diberikan sangat memengaruhi kepuasan dari pelanggan sebuah perusahaan. Akan tetapi, ada beberapa gap atau kesenjangan yang dapat menyebabkan kegagalan dalam penyampaian jasa kepada pelanggan (Tjiptono \& Chandra, 2011). Pada Gambar 1 terlihat ada lima kesenjangan, antara lain: knowledge gap, standards gap, delivery gap, communications gap, dan service gap.

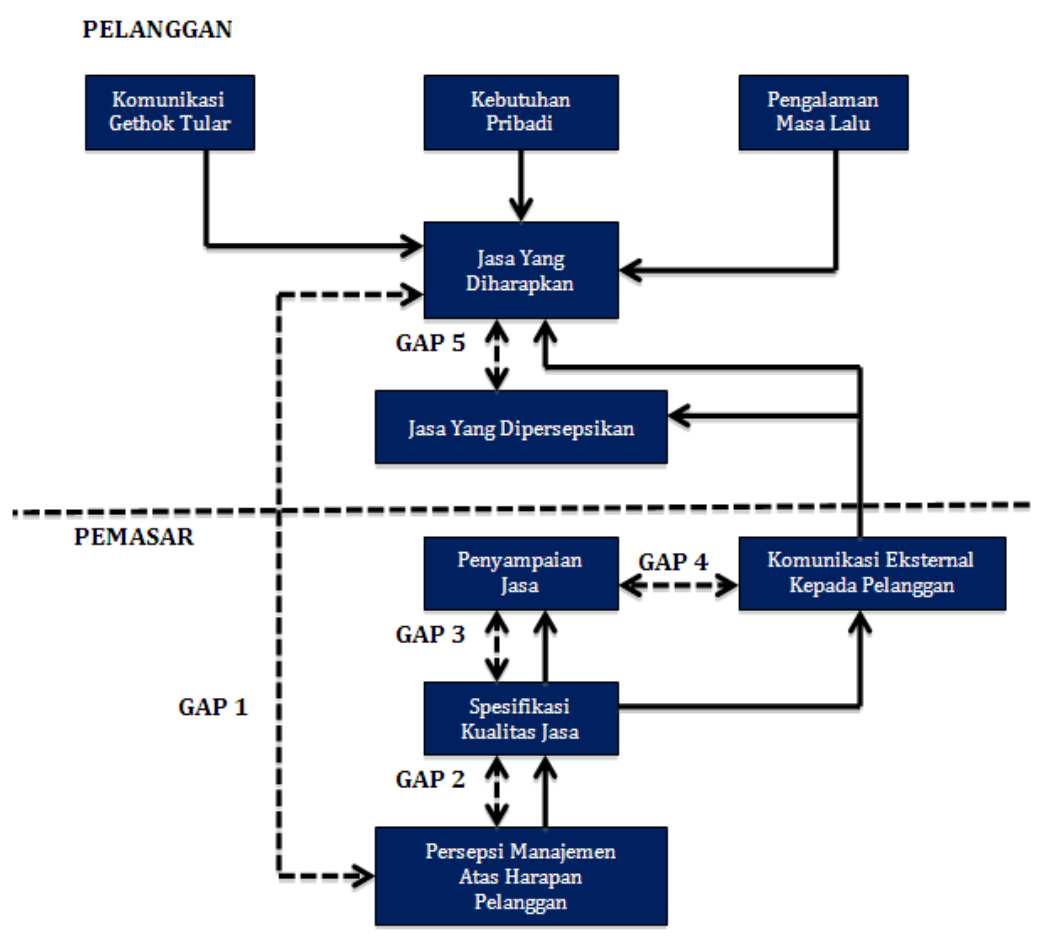

Gambar 1 Model Konseptual Servqual

(Sumber: Tjiptono \& Chandra, 2011) 
Lembaga pendidikan tinggi biasanya dianggap sebagai perusahaan pelayanan publik oleh banyak peneliti karena lembaga pendidikan tinggi didanai pemerintah dan menjadi sasaran kebijakan dan peraturan pemerintah. Kewajiban sosial mereka sering dipandang lebih penting daripada kinerja keuangan mereka. Akibatnya, ada sedikit urgensi bagi mereka untuk terlibat dalam strategi pemasaran organisasi nirlaba. Dalam dekade terakhir ini, bagaimanapun, lembaga pendidikan tinggi telah menyaksikan beberapa perubahan dramatis yang menjadi perhatian besar bagi kesejahteraan masa depan mereka dan kelangsungan hidup (Oldfield \& Baron, 2000). Sekarang ini salah satu keprihatinan utama adalah makin berkurangnya pendanaan pemerintah dan sistem pendanaan berdasarkan kinerja kelembagaan (Cuthbert, 1996a, O'Brien \& Dekan, 1996; Soutar \& McNeil, 1996; Waugh, 2002).

Penurunan dana menyiratkan bahwa lembaga pendidikan tinggi sekarang akan menghadapi masalah dalam mengalokasikan anggaran yang terbatas untuk pengembangan, operasi dan pemeliharaan; dan lembaga pendidikan tinggi harus lebih sadar dengan masalah yang berhubungan dengan faktor biaya (Oldfield \& Baron, 2000), tujuannya adalah masalah pendanaan harus didasarkan pada kinerja kelembagaan. Soutar dan McNeil (1996) berpendapat bahwa meskipun sistem pendanaan mungkin diinginkan karena memperkenalkan tanggung jawab kepada yang lebih tinggi di sektor jasa pendidikan, jenis indikator kinerja yang dipilih oleh pemerintah mungkin tidak benar-benar mencerminkan kinerja kelembagaan yang sebenarnya. Mereka menyatakan bahwa ukuran kualitas berdasarkan variabel proses sering diabaikan, sementara input/output dimensi seperti rasio mahasiswastaf, tingkat kelulusan, dan penerimaan lulusan lebih diutamakan.

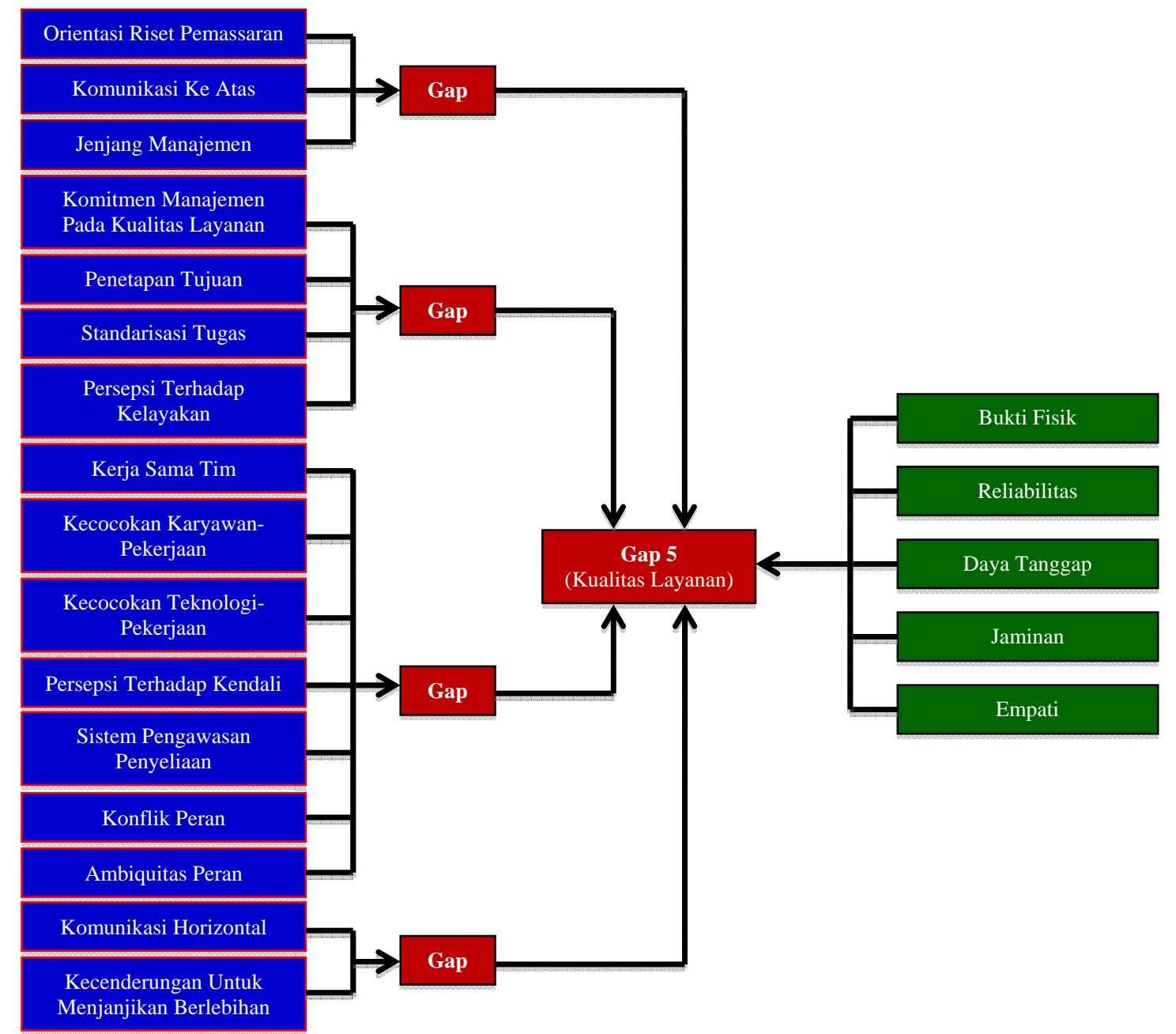

Gambar 2 Extended Model of Service Quality

(Sumber: Tjiptono \& Chandra, 2011:221) 


\section{Penelitian Terdahulu}

Tabel 1 Penelitian Terdahulu

\begin{tabular}{|c|c|c|c|}
\hline Penulis & Jurnal & Judul & Hasil Penelitian \\
\hline $\begin{array}{l}\text { Ozlem } \\
\text { Aydin, Fatma } \\
\text { Pakdil }\end{array}$ & $\begin{array}{l}\text { International Journal of } \\
\text { Faculty of Science and } \\
\text { Letters, Department of } \\
\text { Statistics and Computer } \\
\text { Sciences, Organizacija, } \\
\text { volume 41, number 3, May- } \\
\text { June } 2008\end{array}$ & $\begin{array}{l}\text { Fuzzy Servqual Anaylis in } \\
\text { Airline Services }\end{array}$ & $\begin{array}{l}\text { Dalam industri penerbangan kualitas pelayanan harus diukur dengan } \\
\text { menggunakan semua aspek layanan yang disediakan. Demografi } \\
\text { menunjukkan bahwa ada kesenjangan. Hal ini mendorong peneliti } \\
\text { untuk menganalisis skor Servqual menggunakan bilangan fuzzy. }\end{array}$ \\
\hline $\begin{array}{l}\text { Wann-Yih } \\
\text { Wu, Shin- } \\
\text { Wen Hsiao \& } \\
\text { Hsing-Ping } \\
\text { Kuo }\end{array}$ & $\begin{array}{l}\text { International Journal of } \\
\text { Total Quality Management. } \\
\text { Vol. 15, No. 4, 439-456, } \\
\text { June } 2004\end{array}$ & $\begin{array}{l}\text { Fuzzy Set Theory Based } \\
\text { Decision Model for } \\
\text { Determining Market Position } \\
\text { and Developing Strategy for } \\
\text { Hospital Service Quality }\end{array}$ & $\begin{array}{l}\text { Melalui metode teori himpunan fuzzy dapat memberikan saran untuk } \\
\text { manajer rumah sakit dalam meningkatkan kualitas pelayanan dengan } \\
\text { cara yaitu membandingkan posisi kualitas pelayanan antara rumah } \\
\text { sakit dan pesaing. }\end{array}$ \\
\hline $\begin{array}{l}\text { Lazim } \\
\text { Abdullah \& } \\
\text { Solihah } \\
\text { Khadiah }\end{array}$ & $\begin{array}{l}\text { International Journal of } \\
\text { Latest Trends in Computing, } \\
\text { Vol. 2, page 220, Issue 2, } \\
\text { June } 2011\end{array}$ & $\begin{array}{l}\text { Fuzzy Linguistic for } \\
\text { Measuring Customer } \\
\text { Satisfaction }\end{array}$ & $\begin{array}{l}\text { Skor kualitas pelayanan fuzzy diubah menjadi istilah linguistik } \\
\text { sehingga tingkat kepuasan pelanggan dalam jangka linguistik mampu } \\
\text { mencerminkan persepsi pelanggan. Bilangan fuzzy dan istilah } \\
\text { linguistik efektif digunakan sebagai sebuah metode untuk mengukur } \\
\text { kualitas pelayanan. Identifikasi persepsi konsumen layanan kualitas } \\
\text { dapat membantu manajemen untuk meningkatkan layanan dan } \\
\text { sebagai imbalannya akan meningkatkan klasemen bisnis mereka }\end{array}$ \\
\hline $\begin{array}{l}\text { Lazim } \\
\text { Abdullah }\end{array}$ & $\begin{array}{l}\text { International conference on } \\
\text { business and economic } \\
\text { research, 2nd, } 2011\end{array}$ & $\begin{array}{l}\text { Evaluation of customer } \\
\text { satisfaction: fuzzy linguistic } \\
\text { approach }\end{array}$ & $\begin{array}{l}\text { Skor kualitas pelayanan fuzzy diubah menjadi istilah linguistik } \\
\text { sehingga tingkat kepuasan pelanggan dalam jangka linguistik mampu } \\
\text { mencerminkan persepsi pelanggan. Makalah ini telah berhasil } \\
\text { menunjukkan metode alternatif dalam menangani kepuasan } \\
\text { pelanggan. Evaluasi linguistik fuzzy dapat memberikan sarana baru } \\
\text { untuk meningkatkan kualitas layanan yang diberikan oleh bisnis } \\
\text { berorientasi layanan. }\end{array}$ \\
\hline $\begin{array}{l}\text { Much. } \\
\text { Djunaidi, Eko } \\
\text { Setiawan \& } \\
\text { Tri Haryanto }\end{array}$ & $\begin{array}{l}\text { Jurnal Ilmiah Teknik } \\
\text { Industri, Vol. 4, No. 3, April } \\
\text { 2006, hal. } 139 \text { - } 146\end{array}$ & $\begin{array}{l}\text { Analisis kepuasan pelanggan } \\
\text { dengan pendekatan fuzzy } \\
\text { service quality dalam upaya } \\
\text { peningkatan kualitas } \\
\text { pelayanan }\end{array}$ & $\begin{array}{l}\text { Nilai gap negatif menunjukkan kualitas pelayanan suatu kriteria } \\
\text { kurang baik sehingga perlu ditingkatkan. Bila nilai gap positif, maka } \\
\text { hal itu menunjukkan bahwa persepsi pelanggan terhadap kinerja } \\
\text { suatu kriteria pelayanan melebihi harapannya terhadap kriteria yang } \\
\text { sama. Semakin besar nilai negatif suatu gap pada suatu kriteria } \\
\text { pelayanan, semakin besar pula prioritas peningkatan kualitas } \\
\text { pelayanan dari kriteria pelayanan tersebut. }\end{array}$ \\
\hline $\begin{array}{l}\text { Sushama } \\
\text { Dhote, } \\
\text { Keswani I.P }\end{array}$ & $\begin{array}{l}\text { Int. Journal of Applied } \\
\text { Sciences and Engineering } \\
\text { Research, Vol. 1, Issue 4, } \\
2012\end{array}$ & $\begin{array}{l}\text { Evaluation of service quality } \\
\text { in hospital using fuzzy } \\
\text { reasoning approach }\end{array}$ & $\begin{array}{l}\text { Pendekatan penalaran fuzzy telah diterapkan untuk menentukan } \\
\text { kualitas pelayanan dan membantu dalam penilaian kualitas pelayanan } \\
\text { rumah sakit. Layanan rumah sakit sangat penting karena } \\
\text { berhubungan dengan manusia dan kondisi mental yang buruk selama } \\
\text { pelayanan. Pendekatan yang diusulkan dalam pekerjaan ini sangat } \\
\text { berguna untuk mengetahui status layanan tanpa matematika } \\
\text { kompleks. Pendekatan yang diusulkan akan membantu rumah sakit } \\
\text { serta peneliti untuk patokan prosedur untuk menentukan kualitas } \\
\text { pelayanan di rumah sakit. }\end{array}$ \\
\hline
\end{tabular}

(Sumber: diolah oleh peneliti, 2013)

\section{METODE}

Metode penelitian menurut tingkat eksplanasinya ada tiga hal, yaitu penelitian deskriptif, komparatif, dan asosiatif. Penelitian ini menggunakan penelitian deskriptif. Penelitian deskriptif adalah suatu rumusan masalah yang berkenaan dengan pertanyaan terhadap keberadaan variable mandiri, baik hanya pada satu variabel atau lebih (variabel mandiri adalah variabel yang berdiri sendiri) (Sugiyono, 2012).

Penelitian menggunakan metode servqual, yaitu metode yang digunakan untuk mengetahui kriteria kualitas yang harus ditingkatkan dalam kualitas layanan/jasa berdasarkan gap yang terjadi antara persepsi dan harapan pelanggan. Metode servqual itu sendiri terdiri dari dari dua bagian, yaitu 
penilaian dan pembobotan. Penilaian dilakukan dengan menyebarkan kuesioner dengan seorang partisipan menyatakan persepsi dan ekspektasinya. Pembobotan dilakukan dengan menyebarkan kuesioner dengan seorang partisipan memberikan bobot tertentu.

Tabel 2 Desain Penelitian

\begin{tabular}{ccl}
\hline Tujuan & Jenis penelitian & \multicolumn{1}{c}{ Unit analisis } \\
\hline T-1 & Desikriptif & Mahasiswa Bina Nusantara University kelas Lab. AKB \\
T-2 & Deskriptif & Mahasiswa Bina Nusantara University kelas Lab. AKB \\
T-3 & Deskriptif & Mahasiswa Bina Nusantara University kelas Lab. AKB \\
T-4 & Pemecahan masalah & Kelas Lab. AKB Bina Nusantara University \\
\hline
\end{tabular}

(Sumber: rancangan penulis, 2013)

Keterangan :

T-1 : Mengetahui dan menganalisis ekspektasi mahasiswa jurusan manajemen Bina Nusantara University terhadap kualitas pelayanan/jasa pada kelas Lab. Analisis Kuantitatif Bisnis

T-2: Mengetahui dan menganalisis persepsi mahasiswa jurusan manajemen Bina Nusantara University terhadap kualitas pelayanan/jasa pada kelas Lab. Analisis Kuantitatif Bisnis

T-3 : Mengetahui besarnya gap servqual yang terjadi antara ekspektasi dengan persepsi mahasiswa jurusan manajemen Bina Nusantara University terhadap kualitas pelayanan/jasa pada kelas Lab. Analisis Kuantitatif Bisnis

T-4: Mengusulkan perbaikan kualitas pelayanan/jasa pada Bina Nusantara University dalam kelas Lab. Analisa Kuantitatif Bisnis

Tabel 3 Operasionalisasi Variabel Penelitian

\begin{tabular}{|c|c|c|}
\hline Variabel & Dimensi & Indikator \\
\hline $\begin{array}{c}\text { Kualitas } \\
\text { pelayanan/jasa }\end{array}$ & $\begin{array}{c}\text { Daya tanggap } \\
\text { (Responsiveness) }\end{array}$ & $\begin{array}{l}\text { 1. Fasilitas ruangan memadai } \\
\text { 2. Bahan materi pendukung } \\
\text { 3. Software up to date } \\
\text { 4. Kelengkapan fasilitas peralatan } \\
\text { 5. Kemudahan pemakaian fasilitas peralatan } \\
\text { 6. Kemampuan pengajar } \\
\text { 7. Pengajar berpakaian/tampil rapi. } \\
\text { 8. Latar belakang pengajar } \\
\text { 9. Tepat waktu selama proses pembelajaran } \\
\text { 10. Penyampaian materi } \\
\text { 11. Kesempatan tanya-jawab } \\
\text { 12. Informasi perubahan jadwal } \\
\text { 13. Rasa aman dalam transaksi dengan pengajar } \\
\text { 14. Tanggapan pengajar kepada mahasiswa } \\
\text { 15. Kesopanan } \\
\text { 16. Kepercayaan } \\
\text { 17. Kegiatan belajar kondusif } \\
\text { 18. Penerimaan materi oleh mahasiswa } \\
\text { 19. Pemberian motivasi } \\
\text { 20. Perhatian } \\
\text { 21. Kepedulian } \\
\text { 22. Penyampaian informasi jelas }\end{array}$ \\
\hline
\end{tabular}

(Sumber: diolah penulis, 2013) 
Jenis data yang digunakan dalam penelitian ini adalah data kuantitatif, yaitu data yang berbentuk angka atau data kualitatif yang diangkakan. Metode penelitian kuantitatif dapat diartikan sebagai metode penelitian yang berlandaskan pada filsafat positivism, dan digunakan untuk penelitian pada populasi atau sampel tertentu (Sugiyono, 2012). Sumber data dalam penelitian ini menggunakan data primer dan data sekunder.

Tabel 4 Jenis dan Sumber Data Penelitian

\begin{tabular}{ccc}
\hline Tujuan & Jenis data & Sumber data \\
\hline T-1 & Data kuantitatif & Kuesioner (data primer) \\
T-2 & Data kuantitatif & Kuesioner (data primer) \\
T-3 & Data kuantitatif & Kuesioner (data primer) \\
T-4 & Data kuantitatif & Kuesioner (data primer) \\
T-5 & Data kuantitatif & Kuesioner (data primer) \\
\hline
\end{tabular}

(Sumber: diolah penulis, 2013)

Teknik pengumpulan data yang dilakukan dalam mengumpulkan informasi yang diperlukan dalam penelitian ini: data primer (kuesioner) dan data sekunder (studi pustaka dan browsing internet). Teknik pengolahan data yang digunakan dalam penelitian ini adalah: analisis data seperti uji validitas dan reliabilitas menggunakan SPSS 20.0 dan mengintegrasikan pembobotan dan perangkingan dalam Servqual. Peringkat dilakukan terhadap hasil kuesioner tentang kepuasan pelanggan terhadap kualitas pelayanan/jasa responden. Agar penelitian ini lebih mendetail, perlu adanya peringkat terhadap hasil rekapitulasi kuesioner.

Analisis data penelitian menggunakan metode deskriptif dan data kuantitatif. Untuk menjawab perumusan masalah mengenai sampai sejauh mana tingkat kepuasan pelanggan terhadap kualitas pelayanan/jasa yang diberikan pihak universitas pada kelas Lab. Manajemen sains dalam metode analisis ini digunakan instrumen-instrumen penelitian. Hasil dari penelitian valid jika terdapat kesamaan antara data yang terkumpul dengan data yang sesungguhnya terjadi pada objek penelitian yang diteliti. Sebelum melakukan analisis dengan konsep servqual (service quality) sebagai perbandingan, maka peneliti menggunakan gap analysis terlebih dahulu. Aktivitasnya adalah pertama dilakukan perhitungan manual dengan system gap analysis, dengan persepsi dan harapan dari sisi pelanggan dihitung secara manual dengan alat bantu Microsoft excel. Kemudian, evaluasi dan analisis hasil dari gap analysis tersebut dilakukan, yaitu kesenjangan antara harapan dan persepsi, dari sisi pelanggan.

\section{HASIL DAN PEMBAHASAN}

\section{Uji Validitas dan Reliabilitas}

Kuesioner ditujukan kepada mahasiswa jurusan manajemen Bina Nusantara University yang mengikuti kelas Lab. Analisis Kuantitatif Bisnis (AKB) yang dahulu bernama Metode Kuantitatif Bisnis (MKB). Dalam kuesioner tersebut terdapat dua kolom yang akan diisi yaitu kolom persepsi dan ekspektasi. Dalam setiap kuesioner terdapat lima dimensi Service Quality atau kualitas jasa yaitu dimensi tangible, dimensi reliability, dimensi responsiveness, dimensi assurance, dan dimensi emphaty. 
Tabel 5 Hasil Uji Validitas Persepsi

Item-Total Statistics

\begin{tabular}{|l|r|r|r|r|}
\hline & $\begin{array}{r}\text { Scale Mean if Item } \\
\text { Deleted }\end{array}$ & $\begin{array}{c}\text { Scale Variance if } \\
\text { Item Deleted }\end{array}$ & $\begin{array}{c}\text { Corrected Item-Total } \\
\text { Correlation }\end{array}$ & $\begin{array}{c}\text { Cronbach's Alpha if } \\
\text { Item Deleted }\end{array}$ \\
\hline Butir1 & 63,7667 & 85,702 &, 680 &, 922 \\
Butir2 & 63,9667 & 86,171 &, 924 \\
Butir3 & 64,4000 & 87,903 &, 924 \\
Butir4 & 64,3000 &, 524 &, 927 \\
Butir5 & 63,9333 &, 345 &, 922 \\
Butir6 & 63,9000 & 85,631 &, 925 \\
Butir7 & 64,2333 &, 672 &, 921 \\
Butir8 & 64,2000 & 87,610 &, 472 \\
Butir9 & 64,4333 & 84,806 &, 928 \\
Butir10 & 64,7000 & 84,959 &, 921 \\
Butir11 & 64,6667 & 82,148 &, 922 \\
Butir12 & 64,1333 & 81,540 &, 318 &, 922 \\
Butir13 & 63,9667 & 82,740 &, 677 &, 921 \\
Butir14 & 63,8667 & 83,137 &, 662 &, 919 \\
Butir15 & 63,9667 & 84,189 &, 703 &, 920 \\
Butir16 & 64,0000 &, 787 &, 921 \\
Butir17 & 63,8000 & 84,620 &, 783 &, 922 \\
Butir18 & 63,9333 & 87,545 &, 705 &, 926 \\
Butir19 & 63,9333 & 89,513 &, 656 &, 926 \\
Butir20 & 64,7000 & 85,513 &, 409 &, 922 \\
Butir21 & 64,6667 & 83,321 &, 350 &, 923 \\
Butir22 & 64,9000 & 85,670 &, 622 &, 922 \\
\hline
\end{tabular}

(Sumber: diolah oleh Penulis, 2013)

Tabel 6 Reliability statistics

Reliability Statistics

\begin{tabular}{|c|c|}
\hline Cronbach's Alpha & $\mathrm{N}$ of Items \\
\hline ,926 & 22 \\
\hline
\end{tabular}

(Sumber: diolah oleh penulis, 2013)

Dari tabel diketahui bahwa butir pertanyaan 1 sampai 22 dinyatakan valid dan reliable dengan pertimbangan $\mathbf{r}$ alpha positif dan $\mathbf{r}$ alpha $>\mathbf{r}$ table (0.239).

\section{Kesenjangan GAP Servqual}

Dalam kesenjangan dilakukan perbandingan nilai rata-rata dari bobot tingkat kenyataan atau persepsi pelanggan dengan harapan pelanggan (dalam penelitian ini adalah mahasiswa), yang kemudian dianalisis lebih lanjut. Dalam analisis GAP pertanyaan-pertanyaan dikelompokkan berdasarkan dimensi kualitas jasa, yaitu dimensi tangible, reliability, responsiveness, assurance, dan empathy.

Tabel 7 Hasil Gap Servqual Keseluruhan

\begin{tabular}{|c|c|c|c|c|c|}
\hline No & Statement & Persepsi & Ekspektasi & Gap & Rank \\
\hline \multicolumn{6}{|c|}{ Sub indikator dimensi Tangible } \\
\hline 1 & Fasilitas ruang kelas memenuhi standar & 3,40 & 4,43 & $-1,03$ & 17 \\
\hline 2 & $\begin{array}{l}\text { Setiap mahasiswa/i mendapatkan bahan materi untuk } \\
\text { mendukung kegiatan pembelajaran }\end{array}$ & 3,20 & 4,47 & $-1,27$ & 11 \\
\hline 3 & $\begin{array}{l}\text { Software yang digunakan dalam kegiatan pembelajaran up } \\
\text { to date }\end{array}$ & 2,77 & 4,43 & $-1,67$ & 4 \\
\hline 4 & $\begin{array}{l}\text { Tersedianya peralatan yang mendukung kegiatan } \\
\text { pembelajaran }\end{array}$ & 2,87 & 4,40 & $-1,53$ & 6 \\
\hline 5 & Peralatan yang tersedia mudah dioperasikan oleh & 3,23 & 4,30 & $-1,07$ & 15 \\
\hline
\end{tabular}




\begin{tabular}{|c|c|c|c|c|c|}
\hline \multicolumn{6}{|c|}{ mahasiswa/i } \\
\hline \multicolumn{6}{|c|}{ Sub indikator dimensi Reliability } \\
\hline 6 & $\begin{array}{l}\text { Staff pengajar mampu memberikan penjelasan materi yang } \\
\text { mudah dipahami oleh mahasiswa/i }\end{array}$ & 3,27 & 4,30 & $-1,03$ & 18 \\
\hline 7 & Staff pengajar selalu berpakaian/tampil rapi & 3,14 & 3,78 & $-0,64$ & 21 \\
\hline 8 & Staff pengajar memiliki latar belakang pendidikan yang baik & 2,93 & 4,60 & $-1,67$ & 5 \\
\hline 9 & $\begin{array}{l}\text { Kegiatan belajar mengajar berlangsung sesuai dengan waktu } \\
\text { yang sudah ditentukan }\end{array}$ & 2,97 & 4,47 & $-1,50$ & 7 \\
\hline 10 & $\begin{array}{l}\text { Staff pengajar menyampaikan materi pembelajaran secara } \\
\text { profesional }\end{array}$ & 2,73 & 4,47 & $-1,73$ & 3 \\
\hline \multicolumn{6}{|c|}{ Sub indikator dimensi Responsiveness } \\
\hline 11 & Mahasiswa/i diberi kesempatan untuk bertanya & 2,47 & 4,27 & $-1,80$ & 2 \\
\hline 12 & $\begin{array}{l}\text { Jika terdapat perubahan jadwal, staff pengajar } \\
\text { memberitahukan kepada mahasiswa/i }\end{array}$ & 2,50 & 4,53 & $-2,03$ & 1 \\
\hline 13 & Rasa aman dalam transaksi dengan staff pengajar & 2,64 & 3,26 & $-0,62$ & 22 \\
\hline 14 & $\begin{array}{l}\text { Staff pengajar membantu mahasiswa/i yang mengalami } \\
\text { kesulitan pembelajaran dengan cepat }\end{array}$ & 3,03 & 4,33 & $-1,30$ & 10 \\
\hline \multicolumn{6}{|c|}{ Sub indikator dimensi Assurance } \\
\hline 15 & Staff pengajar berperilaku sopan dalam segala hal & 3,20 & 4,47 & $-1,27$ & 12 \\
\hline 16 & $\begin{array}{l}\text { Staff pengajar mampu menumbuhkan rasa percaya terhadap } \\
\text { mahasiswa/i dalam kegiatan pembelajaran }\end{array}$ & 3,30 & 4,43 & $-1,13$ & 14 \\
\hline 17 & Kegiatan belajar mengajar berlangsung kondusif & 3,20 & 4,57 & $-1,37$ & 9 \\
\hline 18 & $\begin{array}{l}\text { Mahasiswa/i mampu memahami setiap materi yang } \\
\text { diberikan oleh staff pengajar }\end{array}$ & 3,17 & 4,40 & $-1,23$ & 13 \\
\hline \multicolumn{6}{|c|}{ Sub indikator dimensi Emphaty } \\
\hline 19 & $\begin{array}{l}\text { Staff pengajar memberikan motivasi kepada mahasiswa/i } \\
\text { Staff pengajar memberi perhatian penuh pada mahasiswa/i }\end{array}$ & 3,37 & 4,33 & $-0,97$ & 19 \\
\hline 20 & $\begin{array}{l}\text { saat mengajar, seperti tidak mengoperasikan ponsel saat jam } \\
\text { pelajaran }\end{array}$ & 3,23 & 4,30 & $-1,07$ & 16 \\
\hline 21 & $\begin{array}{l}\text { Staff pengajar peduli terhadap kebutuhan yang dikemukakan } \\
\text { oleh mahasiswa/i }\end{array}$ & 3,23 & 4,00 & $-0,77$ & 20 \\
\hline 22 & Staff pengajar menyampaikan informasi dengan jelas & 2,47 & 3,87 & $-1,40$ & 8 \\
\hline
\end{tabular}

(Sumber: diolah oleh penulis, 2013)

Setelah didapatkan nilai gap servqual per-kriteria untuk masing-masing nilai persepsi, ekspektasi dan gap dijumlahkan berdasarkan dimensi.

Tabel 8 Hasil Gap Servqual per Dimensi

\begin{tabular}{clcccc}
\hline No & Statement & Persepsi & Ekspektasi & Gap & Rank \\
\hline 1 & Reliability & 15,04 & 21,62 & $-6,58$ & 1 \\
2 & Tangible & 15,47 & 22,03 & $-6,56$ & 2 \\
3 & Responsiveness & 10,64 & 16,39 & $-5,75$ & 3 \\
4 & Assurance & 12,87 & 17,87 & $-5,00$ & 4 \\
5 & Emphaty & 12,30 & 16,50 & $-4,20$ & 5 \\
\hline
\end{tabular}

(Sumber: diolah penulis, 2013)

Hasil uji adalah sebagai berikut. Uji validitas dilakukan pada semua data, yaitu data berdasarkan hasil kuesioner baik data mengenai persepsi pelanggan dan ekspektasi pelanggan. Sementara hasil uji reliabilitas dapat dinyatakan bahwa semua data (persepsi pelanggan dan ekspektasi pelanggan) adalah reliable. 


\section{SIMPULAN}

Berdasarkan hasil penelitian, didapatkan kriteria dimensi kualitas jasa yang digunakan untuk mengukur kualitas pelayanan/jasa pada kelas Lab. Analisa Kuantitatif Bisnis, Bina Nusantara University. Tujuan penelitian ini untuk mengukur kualitas layanan berdasarkan gap antara ekspektasi dengan persepsi mahasiswa, dimana tingkat kepuasannya diukur menggunakan metode gap analisis. Berdasarkan hasil pengolahan data dapat diketahui bahwa tingkat kualitas layanan yang diberikan pada kelas Lab. Analisa Kuantitatif Bisnis kepada mahasiswa secara keseluruhan belum memuaskan. Dengan hasil gap cukup besar, tentunya pihak Universitas perlu memberikan perhatian khusus pada dimensi yang memiliki gap tertinggi yaitu reliability, tangible dan responsiveness, akan tetapi juga harus tetap memperhatikan pada dimensi lainnya yaitu dimensi assurance dan emphaty dengan tujuan untuk meningkatkan kualitas pelayanan / jasa yang akan diberikan.

\section{DAFTAR PUSTAKA}

Arief. (2007). Pemasaran Jasa \& Kualitas Pelayanan. Malang: Bayu Media Publishing.

Abdullah, L. (2011). Evaluation of customer satisfaction: fuzzy linguistic approach. International Conference on Business and Economic Research, 2 ${ }^{\text {nd }}, 2011$.

Abdullah, L., \& Khadiah, S. (2011). Fuzzy Linguistic for Measuring Customer Satisfaction. International Journal of Latest Trends in Computing, 2(2), 220.

Aydin, O \& Pakdil, F. (2008). Fuzzy Servqual Analysis in Airline Services, 41(3).

A’yunin, Q., \& Surharyanta, D. (2012). Analisis Tingkat Kualitas Pelayanan Jasa Menggunakan Metode Service Quality (Servqual) FUZZY di Instalasi Radiologi Rumah Sakit Umum Daerah (RSUD) Panembahan Senopati Bantul Tahun 2012. KESMAS, 7(1), 1-54.

Bebko, C. P. (2000). Service intangibility and its impact on consumer expectations of service quality. Journal of Services Marketing, 14(1), 9-26.

Buchari, A. (2009). Manajemen Pemasaran dan Pemasaran Jasa. Cetakan ke-8. Bandung: Alfabeta.

Boulding, W., Kalra, A., Staelin, R. \& Zeithaml, V. A. (1993). A dynamic process model of service quality: from expectations to behavioral intentions. Journal of Marketing Research, 30, 7-27.

Boshoff, C. (1997). An experimental study of service recovery options. International Journal of Service Industry Management, 8(2), 110-130.

Cuthbert, P. F. (1996a). Managing service quality in HE: is SERVQUAL the answer? Part1. Managing Service Quality, 6(2), 11-16.

DiDomenico, E., and Bonnici, J. (1996). Assessing service quality within the educational environment. Education Journal, 116(3), 353-359.

Dhote, S., and Keswani I. P. (2012). Evaluation of service quality in hospital using fuzzy reasoning approach. Int. Journal of Applied Sciences and Engineering Research, 1, 4.

Dotchin, J. A., and Oakland, J. S. (1994). Total quality management in services, part 1: understanding and classifying services. International Journal of Quality \& Reliability Management, 11(3), 926. 
Djunaidi, M., Setiawan, E., \& Haryanto, T. (2006). Analisis kepuasan pelanggan dengan pendekatan fuzzy service quality dalam upaya peningkatan kualitas pelayanan. Jurnal Ilmiah Teknik Industri, 4(3), 139-146.

Galloway, L. (1998). Quality perceptions of internal and external customers: a case study in educational administration. The TQM Magazine, 10(1), 20-26.

Gasperz, V. (2012). All in one Management Toolbook. Bogor: Tri Albros.

Gerson, R. F. (2004). Mengukur Kepuasan Pelanggan. Jakarta: PPM.

Ghobadian, A., Speller, S., \& Jones, M. (1994). Service quality: Concepts and models. International Journal of Quality \& Reliability Management, 11(9), 43-66.

Gronroos, C. (2001). The perceived service quality concept a mistake? Managing Service Quality, 11(3), 150-152.

Hoe, T. C. (2004). Measuring student perception of Service Quality in higher education. Dissertation, DBA program of the University of South Australia.

Kandampully, J., \& Butler, L. (2001). Service guarantees: a strategic mechanism to minimise customers' perceived risk in service organizations. Managing Service Quality Journal, 11(2), $112-121$.

Kusuma Dewi, Sri \& Purnomo, H. (2010). Aplikasi Logika Fuzzy untuk Pendukung Keputusan. Cetakan Pertama, Edisi 2. Yogyakarta : Graha Ilmu.

Kellogg, D. L., Youngdahl, W. E. \& Bowen, D. E. (1997). On the relationship between customer participation: two frameworks. International Journal of Service Industry Management, 8(3), 206-219.

Kelsey, K. D. \& Bond, J.A. (2001). A model for measuring customer satisfaction within an academic centre of excellence. Managing Service Quality, 11(5), 359-368.

Kotler, P., \& Amstrong, G. (2008). Prinsip-Prinsip Pemasaran. Cetakan ke-12. Jakarta: Erlangga.

Kotler, P. (2009). Manajemen Pemasaran. Edisi ke-13 Jilid 1. Jakarta: Erlangga.

Kurniasari, A., \& Hadi, C. (2012). Penilaian kualitas Pelayanan Jasa oleh Konsumen Bengkel Resmi Sepeda Motor Honda AHASS UD. Ramayana Motor Surabaya. Jurnal Psikologi Industri dan Organisasi, 1(2).

Lovelock, C. H., \& Wright, L. K. (1999). Principles of Services Marketing and Management. New Jersey: Prentice-Hall.

McColl, R., Callaghan, B., \& Palmer, A. (1998). Services Marketing: a Managerial Perspective. Sydney: McGraw-Hill.

Noel, H. (2009). Consumer Behaviour. Switzerland: AVA.

O'Brien, E. M., \& Deans, K. R. (1996). Educational supply chain: a tool for trategic planning in tertiary education? Marketing Intelligence \& Planning, 14(2), 33-40.

Oldfield, B. M., \& Baron, S. (2000). Student perceptions of service quality in a UK university business and management faculty. Quality Assurance in Education, 8(2), 85-95. 
Parasuraman, A., Zeithaml, V. A., and Berry, L. L. (1994). Reassessment of expectations as a comparison standard in measuring service quality: implications for further research. Journal of Marketing, 58, 111-124.

Parasuraman, A., Berry, L. L., and Zeithaml, V. A. (1991). Refinement and reassessment of the SERVQUAL scale. Journal of Retailing, 67(4), 420-450.

Parasuraman, A., Zeithaml, V. A., \& Berry, L. L. (1988). SERVQUAL: a multiple-item scale for measuring consumer perceptions of quality. Journal of Retailing, 64(1), 12-40.

Roest, H. and Pieters, R. (1997). The nomological net of perceived service quality. International Journal of Service Industry Management, 8(4), 336-351.

Soutar, G., and McNeil, M. (1996). Measuring service quality in a, tertiary institution. Journal of Educational Administration, 34(1), 72-82.

Sarjono, H., \& Julianita, W. (2011). SPSS vs LISREL, sebuah pengantar Aplikasi untuk Riset. Jakarta: Salemba Empat.

Sugiyono. (2012). Metode Penelitian Bisnis. Bandung: Alfabeta.

Taylor, S. A., and Baker, T.L. (1994). An assessment of the relationship between service quality and customer satisfaction in the formation of consumers' purchase intentions", Journal of Retailing, Vol. 70, No. 2, pp. 163-178.

Tjiptono, F dan Chandra, G.; (2011). Service, Quality, and Satisfaction. Edisi ke-3. Yogyakarta: Andi.

Triton, P. B. (2006). SPSS 13.0 Terapan: Reset Statistik Parametrik. Yogyakarta: Andi.

Umar, H. (2008). Riset Pemasaran dan Perilaku Konsumen. Jakarta: Gramedia Pustaka Utama.

Wann-Yih Wu, Shin-Wen Hsiao, \& Hsing-Ping Kuo. (2004). Fuzzy Set Theory Based Decision Model for Determining Market Position and Developing Strategy for Hospital Service Quality._International Journal of Total Quality Management, 15(4), 439-456.

Waugh, R. F. (2002). Academic staff perceptions of administrative quality at universities. Journal of Educational Administration, 40(2), 172-188.

Yamit, Z. (2005). Manajemen Kualitas Produk dan Jasa. Yogyakarta: Ekonesia.

Yamit, Z. (2010). Manajemen Kualitas Produk \& Jasa. Cetakan ke-5. Yogyakarta: Ekonisia.

Zeithaml, V. A. (2000). Service quality, profitability, and the economic worth of customers: what we know and what we need to learn. Journal of the Academy of Marketing Science, 28(1), 67-85. 